\title{
Managing Artificial Intelligence Technology for Added Value
}

\author{
Mohammed Ali Berawi ${ }^{*}$
}

${ }^{1}$ Faculty of Engineering, Universitas Indonesia, Kampus UI Depok, Depok 16424, Indonesia

Many industrial sectors are in the midst of a digital transformation that has emerged from the advancement of information and data technology, enhancing the use of computers and automation with smart and autonomous systems powered by data and machine learning. This revolution has been broadly adopted in industry by initiating the use of digital technologies, sensor systems, intelligent machines, and smart material in its processes.

Some examples of industrial innovation are the invention of artificial intelligence (AI), the deployment of the Internet of Things (IoT)/Internet of Services (IoS), 3D printing/additive manufacturing, machine learning, and the use of Big Data. These have enables the digitization, automation, or integration of service and product value chains. Implementing digitization and automation is believed to help construction transform into a technology-driven industry and keep pace with other industries.

\section{AI Technology Impact}

Many industries, from product manufacturing and construction projects to business services, are now extensively using AI to facilitate industrial automation. AI has become an industry, with more investment and new technologies and applications being produced. It is also creating benefits for other industries by improving performance, enhancing efficiencies, and offering new and extended markets - the digital economy.

As technology progresses, the nature of work in organizations, social relations and interaction, and individual lifestyles are rapidly changing. AI is making organizations provide better customer service and products, changed with the impact of robotics and automation. Automation has already reduced the number of human workers doing repetitive work and increased work in creative industries.

AI facilitates decision-making, creates integrative systems, and simplifies complex mechanisms though automation. For example, a computer-aided design system that uses 3D modelling in project management or design helps increase product or project efficiency and effectiveness and improves communication and collaboration between stakeholders, while the availability of information from sensor networks in the application of the IoT plays an important role in augmenting and improving the quality of decision-making. 3D printing technology is also seen as an innovative strategy with the potential to revolutionize industry, since it is projected to effectively save time, reduce costs, and help protect the environment by generating less material waste. Further, smart 3D printing can be used to teleport an object from one place to another. 
A mobile compact 3D printing machine can produce items to meet everyday needs. The use of blockchain as a group of people sharing data with trust enhances transaction transparency in the blockchain network. Furthermore, machine learning as an artificial approach is used to solve problems such as face and speech recognition, online fraud detection, and automatic language translation. Public transportation services are incorporating AI technology to create self-driving cars, trains, and planes. AI technology is also expected to help us create artificial lifeforms, personal assistants such as Echo and Alexa and human-like robots capable of complex interactions like Valkyrie and Sophia. AI systems are also greatly influencing our communication and interaction. Machine learning models will help us understand context and meaning for and in various languages.

Given the many benefits of technology in project-product—service deliveries, I argue that the value of tomorrow's product or service will not much depend on production cost but rather the intellectual properties involved in designing and creating and product or service.

\section{Advancing Scientific and Technological Capacity Development}

Technologies are invented to improve project, product, and service performance. In this edition, we are pleased to present nineteen selected papers dedicated to technology improvement in science and engineering. The papers consist of various studies that contribute to improving end-result performance.

The first paper, written by V.V. Strokova, P.S. Baskakov, A.M. Ayzenshtadt, and V.V. Nelyubova, proposes a method for silver nanoparticle (AgNP) stabilization in polymer coatings obtained from aqueous acrylic dispersions. The authors argue that the developed coatings using AgNPs, synthesized in propylene glycol in the presence of non-ionic PVP and modified with ammonium hydroxide, demonstrate high inactivation of bacteria.

The next paper, written by T.I. Sari, A.H. Saputra, S. Bismo and D.R. Maspanger, examines the production and resistance test of copolymer DPNR-g-PAN/PS in DME with the influence of acrylonitrile and styrene monomer. The authors argue that the presence of acrylonitrile and styrene increase the mechanical properties of DPNR and DPNR-g-PAN/PS and that increase in the concentration of acrylonitrile decreases rubber swelling and increases its shrinking.

The third paper, written by Y. Astuti, D. Amri, D.S. Widodo, H. Widiyandari, R. Balgis, and T. Ogi, investigates the effect of fuels on the physicochemical properties and photocatalytic activity of bismuth oxide synthesized using a solution combustion method. The authors argue that the photocatalytic activity of bismuth oxide synthesized using urea fuel on the degradation of methyl orange exhibited better photocatalytic activity with a constant degradation rate.

The fourth paper, written by S.J. Munarso, S.I. Kailaku, A. Arif, A. Budiyanto, I. Mulyawanti, K.S. Sasmitaloka, N. Setyawan, K.T. Dewandari, and S.M. Widayanti, investigates the reduction of chili postharvest losses after implementation of an aqueous ozone treatment, perforated packaging, and refrigerated transportation in inter-city distribution. The authors argue that the implementation of the aqueous ozone treatment reduced the postharvest losses of chili by $60.61 \%$.

The fifth paper, written by D. Purnama, Winarto, N. Sofyan, A. Prihastomo, and K. Ito, investigates the microstructure and mechanical properties of AH-36 steel weldment welded using magnesium modified E6013 electrode. The authors argue that with the increase of Mg layer content, the metal-oxygen oxygen level decreases, and the content of Mn and Si increased. 
The next paper, written by F. Citrawati, R. Dwiwandono, and L. Firmansyah, examines the effect of $\mathrm{Ni}$ on the formation of bainite in Fe-Ni lateritic steels through a semi-continuous cooling method. The authors argue that the variation of $\mathrm{Ni}$ in $\mathrm{Fe}-\mathrm{Ni}$ alloys in the range of 0.01 to $4.5 \mathrm{wt} \%$ affects the morphology of bainite formed in the as-treated samples, which then affects their mechanical properties.

The seventh paper, written by D. Idamayanti, W. Purwadi, B. Bandanadjaja, and R. Triadji, investigates the use of rice husk waste as an exothermic material for steel casting. The authors argue that a rice husk sleeve mixed with $12 \mathrm{wt} \%$ binder extended the solidification time; the MEF of 1.69 was achieved.

The eighth paper, written by S. Attanayake, M. Okuya, and K. Murakami, evaluates the effect of spray angle on terrace-truncated nanocone structure formation. The authors argue that the best transparent conductive oxide behavior was obtained from the sample synthesized at the lowest spray angle of $15^{\circ}$ with high conductivity of $2.5 \times 10^{3} \Omega^{-1} . \mathrm{cm}^{-1}$ and high transparency of $82 \%$ in the visible range.

The next paper, written by Yanuar, M.S.G. Putra, M. Akbar, M. Alief, and Fatimatuzzahra, and presents a numerical study on the influence of hydrofoil clearance on total drag reduction in a winged air induction pipe for air lubrication. The authors argue that the reduction of drag force increased to about $10 \%$ compared with bare plate configuration.

The tenth paper, written by M.I. Rosyidi, E.M. Widodo, T.A. Purnomo, M. Setiyo, and D.W. Karmiadji, produces a feasibility study to convert an online fleet from gasoline RON 90 to LPG. The authors argue that investment is feasible and further can assist car owners if the government provides waivers or even exempts taxes and inspection costs.

The eleventh paper, written by R. Woodhead and M.A. Berawi, presents value creation and the pursuit of multifactor productivity improvement. The authors argue that MFP calculations vary during project execution and are valuable to governments in assessing investments and the technological benefits of projects.

The next paper, written by A.S. Muntohar, W. Diana, M.Y. Tafalas, and N.R. Bimantara, investigates the behavior of the flexible plate supported with a SiCC-mortar column on expansive soil. The authors argue that the results indicated that the enlarged column head significantly improved carrying and transmitting the load to the soil.

The thirteenth paper, written by S.H. Siwi, Y.A. Yatmo, and P. Atmodiwirjo, examines the boundary formation of sacred places in Muslim dwellings. The authors argue that the agreement of inhabitants regarding the use of and requirements for the sacred place becomes a way to maintain the social sustainability of the dwelling.

The fourteenth paper, written by S.P. Pradita, P. Ongkunaruk, and T.D. Leingpibul, uses an intervention forecasting approach to improve reefer container demand forecasting accuracy. The authors argue that the adjustment could increase forecast accuracy by $42.39 \%$ and $39.42 \%$ for 20 and 40 foot containers, respectively.

The next paper, written by L. Gozali, M. Masrom, T.Y.M. Zagloel, H.N. Haron, J.A. GarzaReyes, B. Tjahjono, A.P. Irawan, F.J. Daywin, A.F. Syamas, S. Susanto, H.K. Aliwarga, and I.A. Marie, evaluates performance factors of a successful business incubator for Indonesian public universities. The authors argue that information technology, entry criteria, government support and protection, funding and support, a mentoring networking, and university regulations support the performance of a business incubator.

The sixteenth paper, written by A. Widyanti and A. Reyhannisa, presents a human factor analysis and classification system in the evaluation of outpatient medication errors. The authors argue that the main causes of medication error are information overload and fatigue; therefore, computerized systems and the rearrangement of work shift hours are recommended to reduce the errors. 
The next paper, written by H. Iridiastadi, T. Vani, and P.A.R. Yamin, presents a biomechanical evaluation of a patient-handling technology prototype. The authors argue that the PHT prototype resulted in a substantial reduction in compression force at the lumbar (L5/S1) joint.

The eighteenth paper, written by H. Sulistyo, D.P. Priadana, Y.W. Fitriandini, T. Ariyanto, and M.M. Azis, presents the use of glycerol by ketalization reactions with acetone to produce solketal using indion $225 \mathrm{Na}$ as catalyst. The authors argue that a preexponential factor of $1.27 \mathrm{~min}^{-1}$, activation energy of $17.97 \mathrm{~kJ} / \mathrm{mol}$, acetone adsorption equilibrium of 1.05 , and solketal desorption equilibrium of 0.57 were obtained.

The final paper, written by D. Dhaneswara, J.F. Fatriansyah, F.W. Situmorang, and A.N. Haqoh, provides a comparative study of HCL and $\mathrm{CH}_{3} \mathrm{COOH}$ acidification methods and variation of alkaline concentration. The authors argue that fourier transfer infrared spectra characterization shows that synthesized silica has Si-O-Si and Si-O bonds, and an XRD pattern shows that the synthesized silica has an amorphous structure.

I hope that this edition of IJTech conveys some new insights in the way we conduct our research. I am pleased to respond to any comment or enquiry you may have on the direction and content of IJTech, and I invite you to join us in this venture by sending your work for consideration.

With warmest regards from Jakarta,

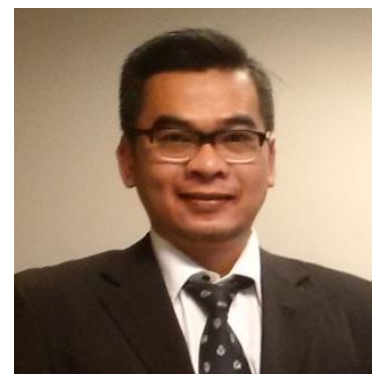

Dr. Mohammed Ali Berawi

Editor in Chief 